\title{
The Emergence of Resilience: Recovery Trajectories in Sleep Functioning After a Major Stressor
}

\author{
Daniel F. Gucciardi ${ }^{1,2}$, Jonas W. B. Lang ${ }^{3,4}$, Robin L. J. Lines ${ }^{1,2}$, Michael T. \\ Chapman $^{1,2}$, Kagan J. Ducker ${ }^{1}$, Peter Peeling ${ }^{5}$, Monique Crane ${ }^{6}$, Nikos Ntoumanis ${ }^{2,} 7$, \\ Sharon K. Parker ${ }^{8}$, Cecilie Thøgersen-Ntoumani ${ }^{2,7}$, Eleanor Quested ${ }^{2,}$, and \\ Philip Temby ${ }^{9}$ \\ ${ }^{1}$ Curtin School of Allied Health, Curtin University \\ ${ }^{2}$ Physical Activity and Well-being Research Group, Curtin University \\ ${ }^{3}$ Department of Human Resource Management and Organisational Psychology, Ghent University \\ ${ }^{4}$ Business School, University of Exeter \\ ${ }^{5}$ School of Human Sciences (Exercise and Sport Science), The University of Western Australia \\ ${ }^{6}$ School of Psychology, Macquarie University \\ ${ }^{7}$ Curtin School of Population Health, Curtin University \\ ${ }^{8}$ Future of Work Institute, Curtin University \\ ${ }^{9}$ Land Division, Defence Science and Technology, Adelaide, South Australia, Australia
}

\begin{abstract}
There is intuitive and practical appeal to the idea of emergent resilience, that is, sustaining healthy levels of functioning or recovering quickly after some degree of deterioration following exposure to heightened risk or vulnerability. Scholars typically utilize mean levels of functioning indices to identify qualitatively distinct latent subgroups of individuals who share similar patterns of change over time. We propose and showcase an alternative, yet complementary operationalization of emergent resilience via temporal changes in within-person variability. Twenty-nine male personnel ( $26.25 \pm 2.67$ years) from the Australian Army who passed a 3-week Special Forces Selection Course provided device-based assessments of sleep functioning for seven nights immediately following course completion. Participants also provided a hair sample for cortisol analysis prior to and immediately after the selection course as an index of accumulated stress, and self-reported their adaptability prior to the 7-day monitoring period. We combined latent growth modeling with an exponential variance function to capture fluctuations around latent means and their change over time. Consistent with our conceptualization of "bounce back" emergent resilience, within-person variability in sleep duration decreased each night by around $10 \%$, which reflects a meaningful small
\end{abstract}

\footnotetext{
This article was published Online First May 24, 2021.

Daniel F. Gucciardi (D) https://orcid.org/0000-0001-54483990

Jonas W. B. Lang (iD https://orcid.org/0000-0003-11153443

Robin L. J. Lines (DD https://orcid.org/0000-0003-36878870

Michael T. Chapman (D) https://orcid.org/0000-00026585-1119
}

Kagan J. Ducker (D) https://orcid.org/0000-0002-4251649X

Peter Peeling (D) https://orcid.org/0000-0002-3895-0015 Monique Crane (iD https://orcid.org/0000-0002-49437962
We are unable to make the raw data open access due to contractual obligations with our funder; researchers interested in obtaining a copy of the raw data can do so by requesting this information from the corresponding author.

The Commonwealth of Australia supported this research through the Australian Army and a Defence Science Partnerships agreement of the Defence Science and Technology Group, as part of the Human Performance Research Network. Sharon Parker was supported by an Austrlian Research Council Laureate Fellowship (FL160100033).

Correspondence concerning this article should be addressed to Daniel Gucciardi, Curtin School of Allied Health, Curtin University, GPO Box U1987, Perth 6845, Curtin, Australia. Email: daniel.f.gucciardi@ gmail.com 
mean decrease over time. We also revealed differential effects of the predictor variables; biological stress primarily influenced the total sleep duration on the first night of the 7-day monitoring period, whereas adaptability largely affected temporal changes in the withinperson residual variances. These findings underscore the importance of synergizing concept, operationalization, and method for the science of human resilience.

Keywords: diary study, hair cortisol concentration, growth curve, military psychology, sleep variability

The dynamic and rapidly changing nature of modern workplaces means that individuals are required to navigate stressors regularly as part of their everyday occupational efforts. Stressors are events that pose heightened risk to optimal functioning because they tax people's resources in ways that may exceed their available reservoirs (Cohen et al., 2019). In occupational settings, stressors include events such as imposed organizational change, bullying, occupational health and safety issues, and co-worker conflicts, just to name a few (Cooper et al., 2001; Ganster \& Rosen, 2013; Razinskas \& Hoegl, 2020). It is well known that stress-an experiential state where the demands of the situation exceed our available resources to cope sufficiently with them (Lazarus \& Folkman, 1984) - is often detrimental for psychological, physical, and social functioning (e.g., Bonde, 2008; Eddy et al., 2017; Starcke \& Brand, 2016). Worldwide estimates indicate the economic costs of occupational stress are substantial (e.g., USD 221 million to 187 billion; Hassard et al., 2018). Thus, it is unsurprising that there exists substantial interest in occupational stressors and factors that enable people to demonstrate resilience to them.

Contemporary perspectives underscore the centrality of temporal dynamics for conceptualizing and operationalizing resilience (Bonanno et al., 2015; Gucciardi et al., 2018; Kalisch et al., 2017). For example, knowing which capacities individuals bring with them to a situation can shed light on protective factors that might maximize the likelihood of positive outcomes when confronted with heightened risk or vulnerability, yet the adaptive nature of these capacities and their mechanisms of action can be understood only when examined within a temporal process of responding to stressors or adversities. As an emergent concept, therefore, resilience reflects a system's trajectory of functioning following exposure to heightened risk or vulnerability (Bonanno \& Diminich, 2013), which is the definition that underpins our work. Trajectories of functioning in response to stress and adversity show considerable variability between people (Bonanno \& Mancini, 2012). Although there are several possibilities, "bounce back" (i.e., initial deterioration in functioning after adversity followed by relatively quick or gradual return to homeostasis) and "withstand" (i.e., degree of healthy functioning is relatively stable) are the two most characteristic trajectories of functioning of emergent resilience (Galatzer-Levy et al., 2018). ${ }^{1}$ This conceptualization and definition embrace emergent resilience as a higher-level manifestation of complex interactions among people and their environment; one that can be considered analogous to a puzzle, where individual pieces (i.e., resilience factors) are fit together in some way (i.e., resilience processes, such as starting with edge pieces and sorting by color) to form an overall picture of their quality of functioning in response to heightened risk or disruption. Whereas existing definitions rely solely on mental health for inferences regarding emergent resilience (Kalisch et al., 2015), we propose that indices of functioning are best operationalized according to the nature of the situation and person

\footnotetext{
${ }^{1}$ Our characterization of "bounce back" and "withstand" trajectories of functioning resemble the "recovery" and "resilience" pathways, respectively, described by GalatzerLevy et al. (2018; see also, Bonanno, 2004). However, we subscribe to the conceptualization of "bounce back" resilience with regard to homeostasis, rather a return to some pre-existing capacity or level (Bonanno, 2004), because it offers a comprehensive representation of the functioning of a system (e.g., one's pre-event level of functioning may actually be suboptimal) and provides commonality with the "withstand" trajectory of resilience. By definition, homeostasis represents stability in a system's functioning while adjusting to dynamic conditions. The definition of complete stability depends on the indicator of functioning as well as personal and situational factors. Key here is the notion of stabilization, which can be evidenced via decreases in the degree of fluctuation in markers of functioning over time, irrespective of knowledge of one's pre-event levels or the ideal zone of homeostasis.
} 
(e.g., adversity type, developmental stage). For example, work productivity might be an appropriate indicator of functioning for employees during a period in which they are dealing with substantial work demands, whereas psychological health might be a salient indicator of functioning for children whose parents are undergoing a divorce. We focus on sleep as a broad category of resilient functioning in this study because of the wide-ranging effects of this behavior on physical and mental health (Firth et al., 2020; Irwin, 2015; Yin et al., 2017). Irrespective of the nature of the context (e.g., type of stressor experienced by individuals), scholars consider sleep as a salient indicator of resilient functioning because it characterizes an important element of mal/adaptive outcomes following exposure to extreme or chronic stress (Liu et al., 2017; Parrino \& Vaudano, 2018).

The operationalization of resilience as an emergent outcome is complex because it demands consideration of interactions between person, context, and time (Kozlowski et al., 2013). We showcase a new approach by examining within-person variability in a contextually salient indicator of functioning after a major stressor, utilizing an innovative statistical approach to capture these temporal dynamics and their potential determinants. In so doing, our work contributes to the science of resilience in four ways. First, we provide a novel operationalization that synergizes concept and method whereby the emergent outcome of "bounce back resilience" is inferred via temporal changes in within-person variability that support an interpretation of stabilization in the markers of functioning. Within-person or intra-individual variability in longitudinal data is typically considered a nuisance factor, yet this variation provides rich information about the in/stability of a system that is absent from means alone (Kuppens \& Yzerbyt, 2014; Lester et al., 2019; McNeish, 2020). Two people can be equivalent in terms of mean levels of sleep functioning over time, for example, yet differ meaningfully with regard to the magnitude of fluctuations around this average (e.g., low variability vs. high variability; see Figure 1). People whose sleep varies substantially-just like many other cognitive, emotional, and biological factors (e.g., Houben et al., 2015; Segerstrom et al., 2017)—are at increased risk of a range of health and behavioral issues (Bei et al., 2016), including perceptions of stress (Veeramachaneni et al., 2019). Perhaps most salient for the present study, sleep variability is an important determinant of mental and physical functioning above habitual sleep patterns for duration, efficiency, and timing (Bei et al., 2016).

\section{Figure 1}

Example Hypothetical Scenarios in Which Individuals Share Approximately the Same Mean for Sleep Duration (y Axis) Though Differ in Their Variability Over Time (x Axis)

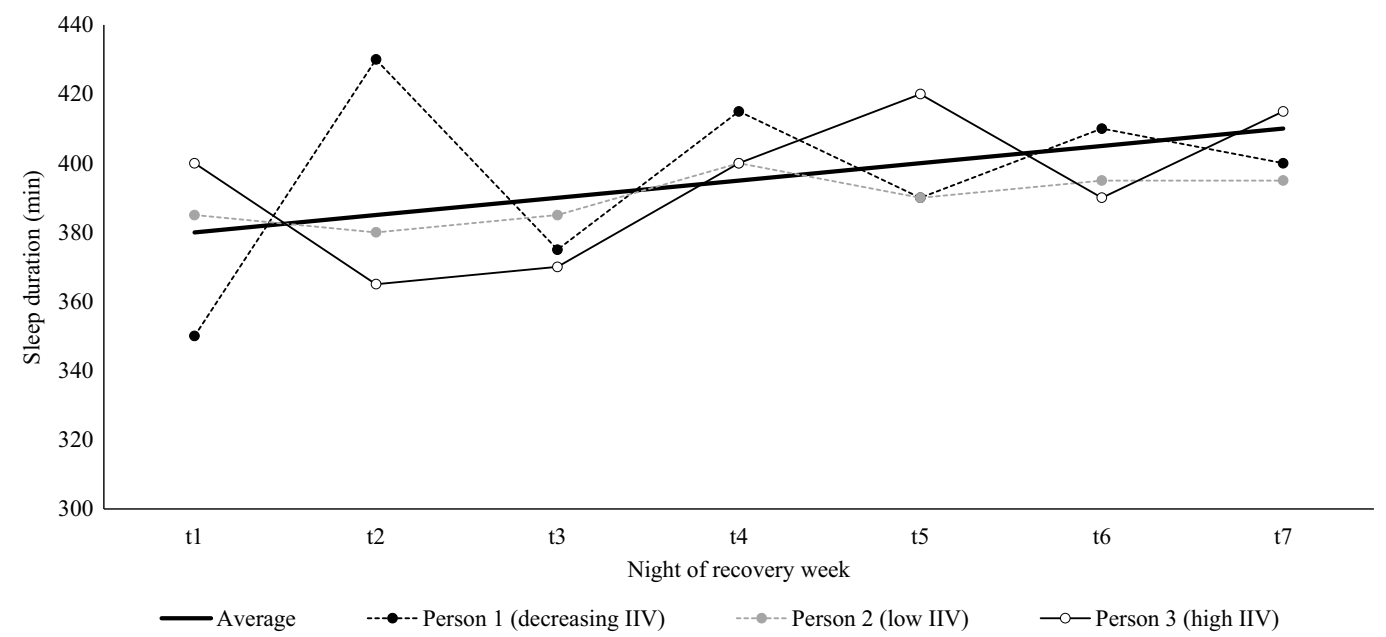

Note. $\quad$ IIV = intra-individual variability. 
Low within-person variability might be indicative of resistance to external (e.g., sleeping in an unusual environment) or internal (e.g., regulatory strategies) forces, whereas high variability might reflect maladaptive responses to them. In such cases, one might erroneously conclude that individuals displayed emergent resilience based on their average mean-level trajectory of total sleep duration over time alone.

Second, we explicitly consider the salience of context and time for the operationalization of indicators of emergent resilience because within-person variability can characterize vulnerability or resilience, depending on situational factors. Take the case of emotions, for example, where high variability might reflect synchronicity of emotional and contextual dynamics-referred to as emotional flexibility - which is essential for psychological health and well-being (Kashdan \& Rottenberg, 2010). Indices of within-person variability offer complementary perspectives of emergent resilience and, therefore, potential for advancing theory and practice, yet it demands congruency between concept, operationalization, and method. We focus on temporal changes in within-person variability in sleep functioning across a 7-day temporal frame as an indicator of emergent resilience among a healthy, nonclinical sample exposed to a major stressor. In this context, reductions in fluctuations of sleep functioning over time provide a means by which to make inferences regarding "bounce back" emergent resilience because they characterize stabilization of the system (see Person 1 in Figure 1). Irrespective of the nature of the context (e.g., type of stressor experienced by individuals), scholars consider sleep broadly as a salient indicator of resilient functioning because it characterizes an important element of mal/adaptive outcomes following exposure to extreme or chronic stress (Liu et al., 2017), particularly in military contexts (Nindl et al., 2018). Practically, sleep functioning is an important consideration for employee performance and health because sleep disturbances and problems are a risk factor for work injuries (Uehli et al., 2014), impairments to cognitive functioning (Fortier-Brochu et al., 2012; Lim \& Dinges, 2010), poor health (e.g., anxiety, fatigue), affective outcomes (e.g., work engagement, job satisfaction), and job performance (e.g., task, safety; Litwiller et al., 2017).
Sleep is considered an important marker of resilience within military contexts (Nindl et al., 2018). We focused on sleep variability as the primary metric of resilient functioning in this study because it maximizes the congruence between the stressor experience and outcome. The stressor at the heart of this study was a 3-week military selection course designed to identify suitable candidates for Special Forces training, where candidates are exposed to numerous situations designed to simulate the harsh and unpredictable nature of combat environments (e.g., cognitive and physical exhaustion). Selection courses for entry into Special Operations of Military Forces worldwide are known for pushing candidates to the absolute limits of human endurance; sleep disruption and deprivation are core to achieving this goal. ${ }^{2}$ First, candidates are often woken up in the middle of the night to complete tedious cognitive (e.g., solve complex problems) and physical tasks (e.g., undertake lengthy physical training sessions). Second, there are several periods within the selection course where candidates are sleep deprived and expected to execute demanding mental (e.g., write essay, recall critical information) and physical challenges (e.g., traverse long distances over rugged terrain carrying heavy loads). The week after the selection course provides successful candidates with the opportunity to recover physically and psychologically in preparation for the start of specialist training that spans several months and which incorporates numerous stressor experiences. Accumulating sufficient sleep quantity and efficiency during this week is essential for subsequent training because it underpins cognitive performance of complex tasks (Lim \& Dinges, 2010; Wickens et al., 2015). Equally, poor sleep prior to future stressor exposure - as was the case for our sample-can amplify the potential negative effects of such experiences (Parrino \& Vaudano, 2018). Stress increases the likelihood of sleep disturbances (Bei et al., 2016; Kim \& Dimsdale, 2007), including within-person variability in total sleep duration (Vidal Bustamante et al., 2020), making indices of sleep functioning ideal for analyses

\footnotetext{
${ }^{2}$ Interested readers are referred elsewhere for detailed descriptions of such courses including documentaries (https://www.imdb.com/title/tt1786116/) and firsthand reflections (Couch, 2008).
} 
of emergent resilience in response to a major stressor where a return to typical functioning is required. ${ }^{3}$

Third, we demonstrate the application of an innovative statistical model that permits a contemporaneous assessment of temporal changes in and predictors of means and variability. Among resilience researchers, the modal approach to studying heterogeneous trajectories of functioning following stressor or adversity experiences is via growth mixture models (Galatzer-Levy et al., 2018). In essence, this statistical framework facilitates the identification of qualitatively distinct latent subgroups of individuals who share similar patterns of growth or change over time, and tests the meaningfulness of hypothesized determinants of profile membership (Infurna \& Grimm, 2017). This approach is appropriate when the objective is to discover the number and shape of growth patterns that distinguish latent subgroups within a sample and the proportion of people within each profile. However, scholars have questioned the interpretability of mixture profile trajectories (e.g., homogeneity of variance and slope variances are set to zero meaning all individual trajectories within a class are the same) and proposed growth curves as a complementary approach because they maximize insight into variations between people in the rate of temporal change (Infurna \& Luthar, 2018). Briefly, growth curves capture the shape, rate, and magnitude of within-person change over time averaged among the sample in terms of a starting point (intercept) and trajectory (slope), and between-person variability around these fixed effects (for a review, see Grimm \& Ram, 2018). As we demonstrate in this study, temporal changes in within-person residual variances over time are an underutilized feature of growth curve models that can shed new light on emergent resilience when considered alongside mean levels. In this context, therefore, reductions in one's sleep functioning variability over time can be considered reflective of stabilization in markers of functioning and therefore an emergent resilience outcome.

Hypothesis 1: In the absence of prior work, we conservatively hypothesized a smallto-moderate "bounce back" effect in the vicinity of $10 \%-15 \%$ reductions in the residual variance at each assessment.
Our final contribution is that we examine the salience of a biological marker of stress and a psychological indicator of adaptive selfregulation capacity as predictors of temporal changes in mean levels and within-person variability in sleep functioning. Hair cortisol concentration is widely utilized for assessments of chronic activation of the hypothalamicpituitary-adrenal (HPA) axis, as triggered by physical and cognitive stressors (Skoluda et al., 2012; Stalder et al., 2017). Stress represents a risk factor for optimal sleep functioning (Bei et al., 2016; Vidal Bustamante et al., 2020). Within the context of the present study, chronic activation of the HPA axis prior to and during the selection course may elicit carryover effects to the recovery week because of circadian misalignments, cognitive disruptions (e.g., rumination), and hyperarousal (Hirotsu et al., 2015; Kim \& Dimsdale, 2007; Sadeh \& Gruber, 2002). In addition, adaptability is particularly salient in circumstances such as those in the present study where individuals are unable to disengage from their primary goal or change their path substantially because of external constraints, such as programming or sleeping in an unusual environment (Martin et al., 2012). We adopt the conceptualization of adaptability as a capacity or potential for action, which is distinct from the process of adapting (i.e., behavioral enactment of adjustments or modifications) and associated adaptation outcomes (Maynard et al., 2015). Formally defined, adaptability captures the degree to which individuals can modify cognitive, emotional, and behavioral strategies in response to stimuli that are novel and/or uncertain in nature (Martin et al., 2012). Conceptually, individuals with higher levels of adaptability capacities may be better positioned to synchronize their self-regulatory processes with the nature of the situation and contextual temporal dynamics

\footnotetext{
${ }^{3}$ Scholars have examined the links between indices of sleep functioning and resilient outcomes (e.g., self-reported general health, health care utilization) among military personnel (Seelig et al., 2016), which has supported calls for the inclusion of sleep hygiene strategies as part of resilience training programs (Germain \& Dretsch, 2016). Our approach differs from this work in that we conceptualize resilience as an emergent outcome of dynamic person-situation interactions over time that can be operationalized via metrics of sleep functioning in response to a major stressor.
} 
than people with lower levels of this potential for action.

Research Question 1: Owing to the exploratory nature of the interaction tests, we proposed a research question rather than hypothesis; that is, to what extent do (RQ1a) accumulated stress and (RQ1b) adaptability affect the degree of temporal changes in within-person variability in estimates of sleep functioning over the 7-day assessment period?

\section{Method}

\section{Participants}

In total, 29 male personnel $(26.25 \pm 2.67$ years) from the Australian Army who passed a 3-week Special Forces Selection Course took part in this study. The intake and number of successful candidates for one annual administration of the course determined our sample size for this study. Power simulations indicated that this sample size is sufficiently sensitive $(>80 \%$ power) to detect small-to-moderate effects (on average, $10 \%$ reduction in the residual variance at each assessment) for the primary hypothesis, and moderate-to-large effects for the interaction tests regarding the influence of accumulated stress and adaptability on temporal changes in sleep functioning (Lang et al., 2019). The code and outputs of these power simulations are located on the Open Science Framework (OSF: https://osf.io/ cg6ne/).

\section{Measure}

\section{Sleep Duration and Efficiency}

We captured two indices of sleep functioning using a triaxial accelerometer (GENEActiv Original; Activinsights Ltd., Kimbolton, Cambs, U.K.) worn on the non-dominant wrist for $24 \mathrm{hr} /$ day configured with a sampling frequency of $66.7 \mathrm{~Hz}$. Raw accelerometer data were processed using the $\mathrm{R}$ package GGIR version 3.3.3 (https://cran.r-project.org/web/packages/GGIR/) because it permits robust detection of sleep duration (van Hees et al., 2015) even in the absence of self-reported diary information (van Hees et al., 2018). The sleep time window represents the longest inactivity block; movement is distinguished from non-movement using the 10th percentile of an individual's threshold based on 5-min rolling median of the absolute change in the $z$-axis (dorsal-ventral direction when the wrist is positioned in the anatomical position) across a 24-hr period (van Hees et al., 2015). Sleep duration is calculated as the sum of all episodes within the sleep period time window with a change in the $z$-axis of less than $5^{\circ}$ lasting at least $5 \mathrm{~min}$. Sleep efficiency is calculated as sleep duration divided by the total available time within a sleep period time window.

\section{Hair Cortisol}

To assess hair cortisol concentration (HCC), we sampled hair strands from the posterior vertex region of the head because this region has the least variation in the average growth of $1 \mathrm{~cm}$ per month (Cooper et al., 2012). Briefly, we used a small wooden peg to secure in place hair segments prior to cutting at root end using fine medical scissors. Hair samples were stored in aluminum foil at room temperature prior to analysis, where they were analyzed in duplicate for cortisol using a validated, commercially available enzymelinked immunosorbent assay (ELISA; Salimetrics, USA) by Stratech Scientific (pre-selection and recovery week intra-assay variability $=4.9 \%$ and $5.3 \%$, inter-assay variability $=5.6 \%$ and $5.9 \%$ ).

\section{Adaptability}

Participants responded to nine items to indicate the degree to which they modify cognitive, emotional, and behavioral strategies in response to stimuli that are novel and/or uncertain in nature, using a 7-point scale anchored by strongly disagree (1) and strongly agree (7) (Martin et al., 2012). Originally developed within the context of education, the tool contains items that are "context neutral" and therefore can generalize to other achievement contexts. Sample items include "I am able to think through a number of possible options to assist me in a new situation" (cognitive), "I am able to reduce negative emotions (e.g., fear) to help me deal with uncertain situations" (emotional), and "To assist me in a new situation, I am able to change the way I do things if necessary" (behavioral). 


\section{Procedure}

Defence Science and Technology Group's human research ethics committee approved this study prior to execution. Participants who took part in this study were sampled from a pool of candidates paneled on a 3-week Special Forces Selection Course $(N=143) .{ }^{4}$ Upon arrival at the military base, candidates were issued with relevant equipment and a unique identification number for the selection course. We subsequently briefed candidates about the nature of the study in groups of approximately 15-20 within a demountable office space. Consenting candidates first provided a hair sample $(1.5 \mathrm{~cm}$ for 6 weeks of stress accumulation) and then moved to an adjacent demountable office space where they completed a survey package. Once candidates had completed the survey, they handed it back to the researchers and were thanked for their participation. Candidates who passed the selection course completed the 7-day recovery week in Barracks at an Australian Army military base. We met participants around 06:00 on the first morning of their recovery week, at which point they completed a survey, provided a hair sample ( $1 \mathrm{~cm}$ for 4 weeks of stress accumulation), and received their GENEActiv. Participants were instructed to wear their GENEActiv watch for $24 \mathrm{hr} /$ day for the following 7 days. Our focus on a 7-day temporal period in this study is consistent with recommendations for assessing within-person variability in indicators of sleep functioning (Rowe et al., 2008). We downloaded sleep data using the GENEActiv software (version 3.1), with raw.csv files converted into.bin files for data processing.

\section{Statistical Analysis}

We examined the primary hypothesis and research question within a mixed-effects modeling framework using an adaptation of the consensus emergence model to capture temporal changes in within-person residual variances of sleep functioning (Lang et al., 2018). Briefly, this statistical model combines fixed (intercept and slope means) and random (intercept and slope variance, their covariance, and residual variance of outcome) effects of traditional latent growth models with an exponential variance function (Pinheiro \& Bates, 2006) to capture fluctuations around these latent means and their change over time. Coding the temporal trend in one unit intervals from a starting point of zero (e.g., 0,
$1,2,3)$ provides a convenient interpretation of changes in residual variance $\left(\delta_{1}\right)$; negative or positive values reflect a linear decrease or increase in the magnitude of residual variance for each assessment, respectively, whereas values around zero capture residual stability. The meaningfulness of change in residual variance can be tested using a log-likelihood ratio test in which a null model is compared with a model that includes residual variance change (Lang et al., 2018). We also examined HCC prior to the selection course and the start of recovery week alongside selfreported adaptability as predictors of mean differences in sleep and residual variance change. These models included the main effect of the predictor at baseline $\left(\delta_{2}\right)$ and its interaction with time $\left(\delta_{3}\right)$. The addition of these predictors to the fixed and random effects components of the model can be tested using the log-likelihood ratio test. For all models, we calculated $R_{L R}^{2}$ to provide an indication of the overall variance explained (Lang et al., 2019; Magee, 1990). We performed these statistical analyses in $\mathrm{R}$ ( $\mathrm{R}$ Development Core Team, 2018) using the nlme package (https:// cran.r-project.org/web/packages/nlme/index.html) and restricted maximum likelihood estimation (full details of these analyses are provided on the OSF: https://osf.io/cg6ne/).

\section{Results}

\section{Descriptive Statistics and Correlations}

The means, standard deviations, and bivariate correlations among study variables are presented in Table 1. Briefly, these descriptive statistics indicate that participants, on average, accrued between 386 and 426 min of sleep per night, and that variation around this group mean decreased over the course of the recovery

\footnotetext{
${ }^{4}$ Data collected with the total sample has been employed in a previous publication (Gucciardi et al., 2021), however, these outputs differ with regard to the (a) research questions, (b) study variables, and (c) theoretical frameworks. For comparison, we previously examined mental toughness as a determinant of behavioral perseverance in Special Forces selection whilst accounting for chronological age and a biological marker of approximately 6 weeks of accumulated stress, and couched this study within the context of conceptual work on goals, stress, and mental toughness. Here we focus on sleep variability as an indicator of trajectories of emergent resilience after a stressful event, and examine psycho-physiological determinants of this variability.
} 


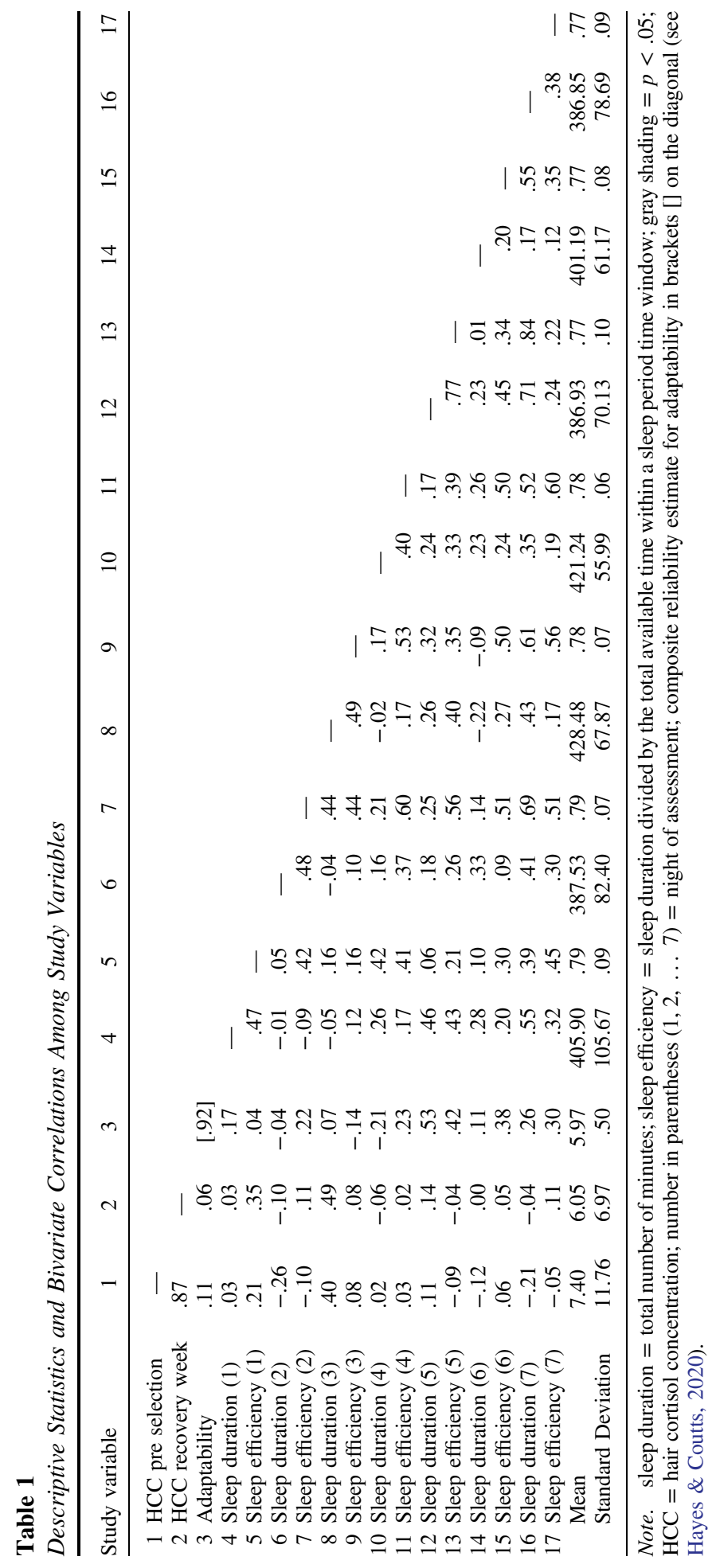


week. Sleep duration and efficiency were moderately correlated on each night indicating a positive association between these two indices of sleep functioning.

\section{Emergent "Bounce Back" Resilience}

Visual depictions of individual level growth trends for total sleep duration and efficiency are provided in Figures 2 and 3, respectively. Model fit statistics and parameter estimates of within-person variability modeling with sleep duration are presented in Table 2. Briefly, the intercept represents the average total amount of sleep accrued on the first night ( 412 min), whereas the slope characterizes the average rate of change per night across the 7-day period ( $\sim 3 \mathrm{~min}$ decrease). For sleep duration, the likelihood test and increased explained variance $\left(\Delta R_{L R}^{2}=5 \%\right)$ supported the superiority of the model including a variance function, when compared with one excluding it. Consistent with Hypothesis 1, within-person variability in sleep duration decreased each night by around $10 \%$, on average, which coincides with a meaningful small mean decrease over time.

\section{Biological Stress and Adaptability as Predictors of Emergent Resilience}

HCC prior to the 3-week selection course and at recovery week both explained unique variance $\left(\Delta R_{L R}^{2}=57 \%\right.$ and $\left.\Delta R_{L R}^{2}=55 \%\right)$, yet the likelihood test indicated the addition of the interaction term with time was statistically trivial. With regard to RQ1a, an examination of the parameter estimates indicated that $\mathrm{HCC}$ contributed mostly to the prediction of the intercept (e.g., $\left.\Delta v_{00} \sim 350\right)$. For RQ1b, self-reported adaptability added unique variance $\left(\Delta R_{L R}^{2}=8 \%\right)$ and improved model fit; the time-by-predictor interaction term indicates that the within-person variability effect is stronger over time when adaptability is high. In other words, candidates with self-reported adaptability one standard deviation above the mean evidenced the greatest decrease in sleep variability across the recovery week (see Figure 4). ${ }^{5}$

\section{Discussion}

Synergies between concept, operationalization, and method are essential for advancing knowledge of emergent resilience. We showcased an underutilized feature of growth curve models that provides an alternative yet complementary perspective on the temporal dynamics of emergent resilience and, in so doing, offered three key contributions to theory and research. First, our findings demonstrated the importance of considering mean levels and within-person variability of indicators of functioning for inferences regarding emergent resilience over time and determinants of these temporal features. Second, we showcased the importance of explicit considerations of time and context for synergizing elements of substance and method for the science of emergent resilience. Third, we demonstrated empirically that the phenomenon of emergent resilience can be observed in healthy samples exposed to a major stressor, specifically with regard to stabilization in markers of functioning via decreases in the degree of fluctuations over time.

Conceptualized as an emergent outcome of dynamic person-situation interactions, resilience can be inferred only via indices of functioning after some experience or event that is characterized by heightened risk or vulnerability (Bonanno et al., 2015; Gucciardi et al., 2018; Kalisch et al., 2017). In contrast to past work that has focused on identifying qualitatively distinct latent subgroups of individuals who share similar temporal patterns in mean levels of functioning indicators over time (Galatzer-Levy et al., 2018; Infurna \& Grimm, 2017), we proposed a new conceptualization and operationalization of emergent resilience via temporal changes in within-person variability in functioning that reflect stabilization in system's functioning while adjusting to dynamic conditions. Our findings showed that participants, on average, experienced $10 \%$ reductions in residual variance estimates of total sleep duration each night across the 7-day period, which aligns with our conceptualization of a bounce back emergent resilience trajectory. An inspection of individual trajectories reinforced the importance of modeling changes in both mean levels and within-person variability for inferences regarding emergent resilience, because there were several participants whose growth trend was relatively stable or flat, yet

\footnotetext{
${ }^{5}$ Owing to minimal variation in sleep efficiency, we experienced model convergence issues and were unable to execute this analysis (see Table 1).
} 
Figure 2

Individual Temporal Trajectories of Sleep Duration (Minutes)

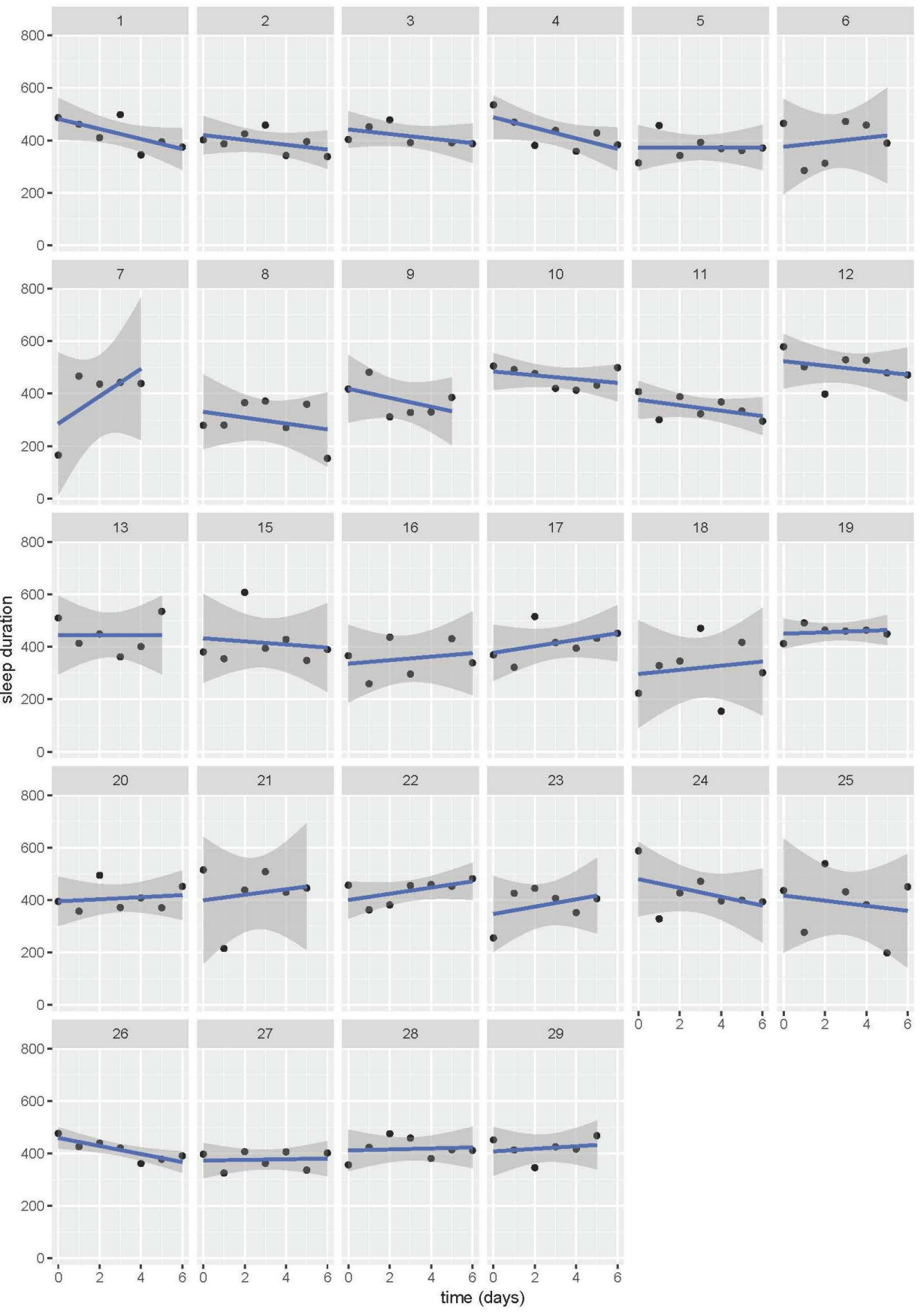

Note. Gray shade represents the $95 \%$ confidence intervals around the regression slope, given random sampling (see here: https://github.com/wilkelab/ungeviz/blob/master/README.md\#bootstrapping). See the online article for the color version of this figure. 


\section{Figure 3}

Individual Temporal Trajectories of Sleep Efficiency
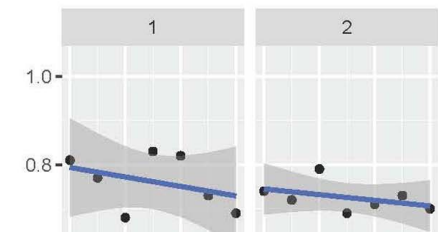

$0.6=$
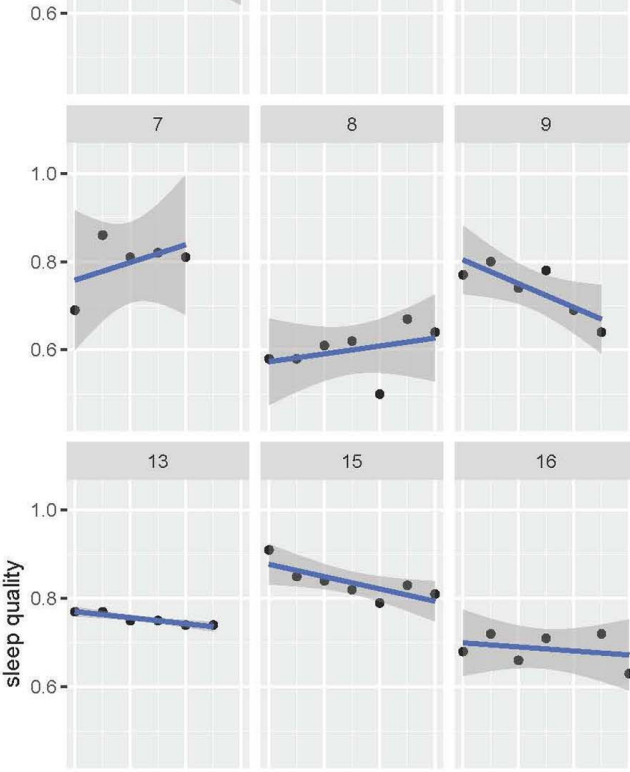

20
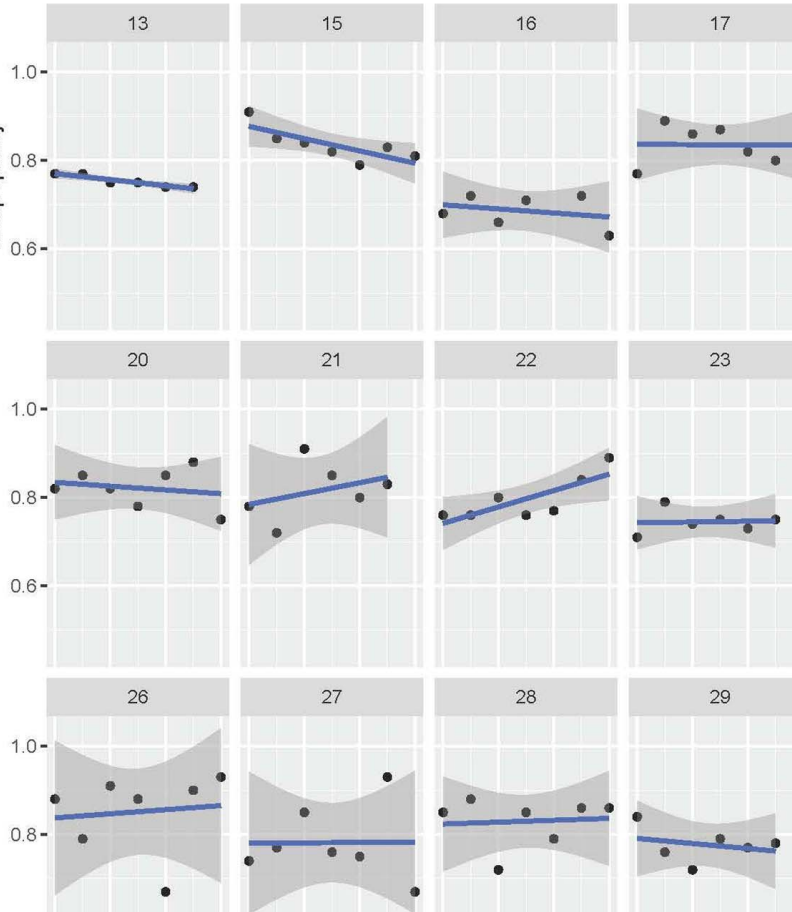

0.6
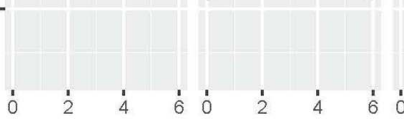
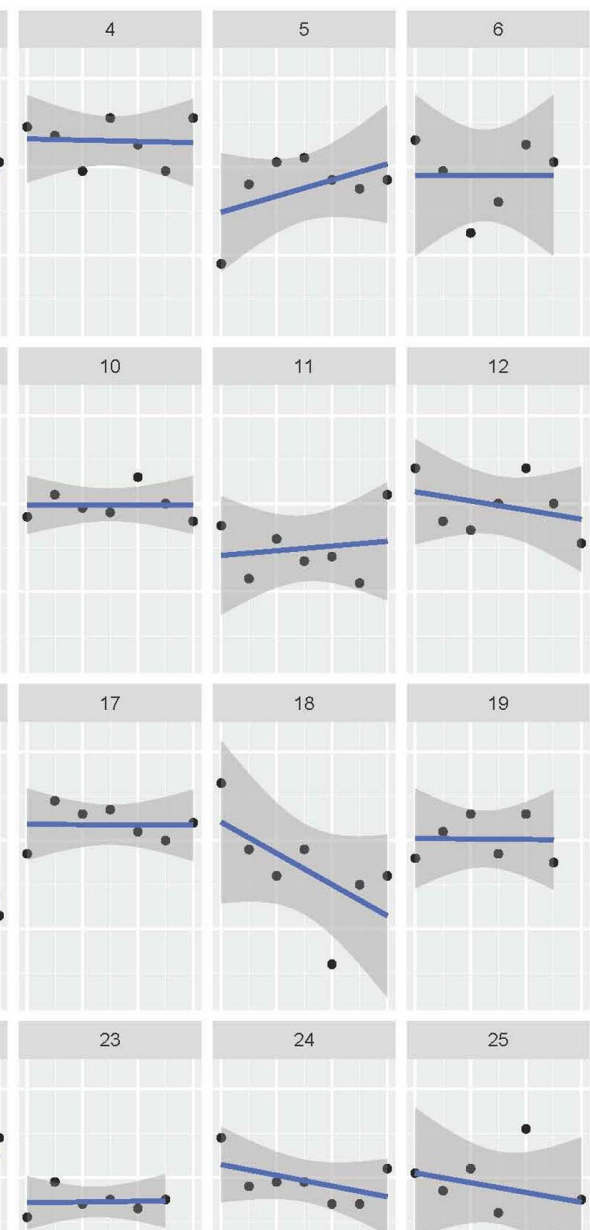

24
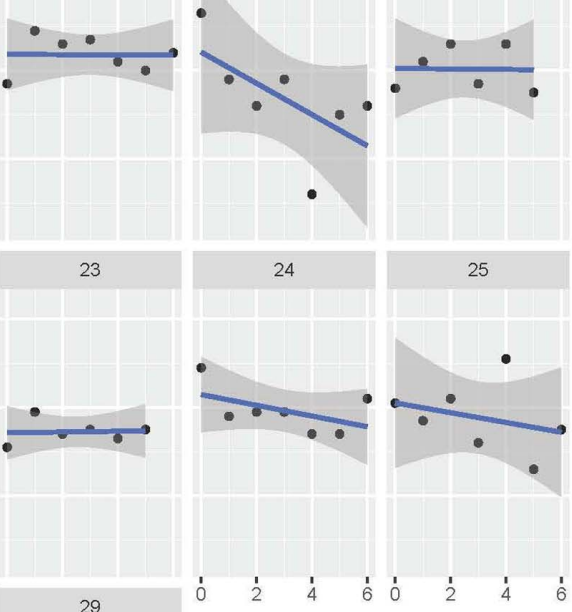

Note. Gray shade represents the $95 \%$ confidence intervals around the regression slope, given random sampling (see here: https://github.com/wilkelab/ungeviz/blob/master/README.md\#bootstrapping). See the online article for the color version of this figure. 
GUCCIARDI ET AL.

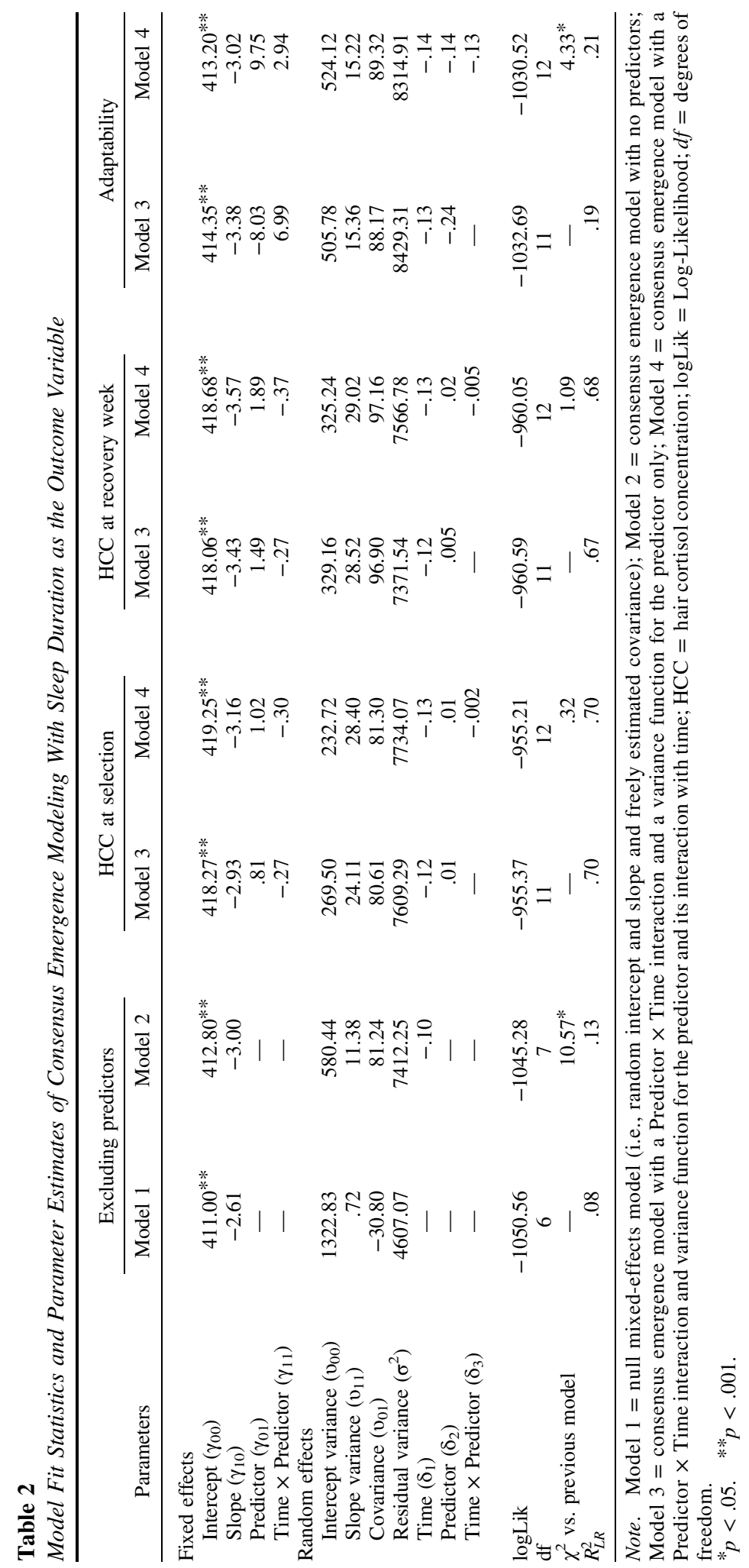


Figure 4

Visual Depiction of the Time $\times$ Predictor Interaction With Self-Reported Adaptability

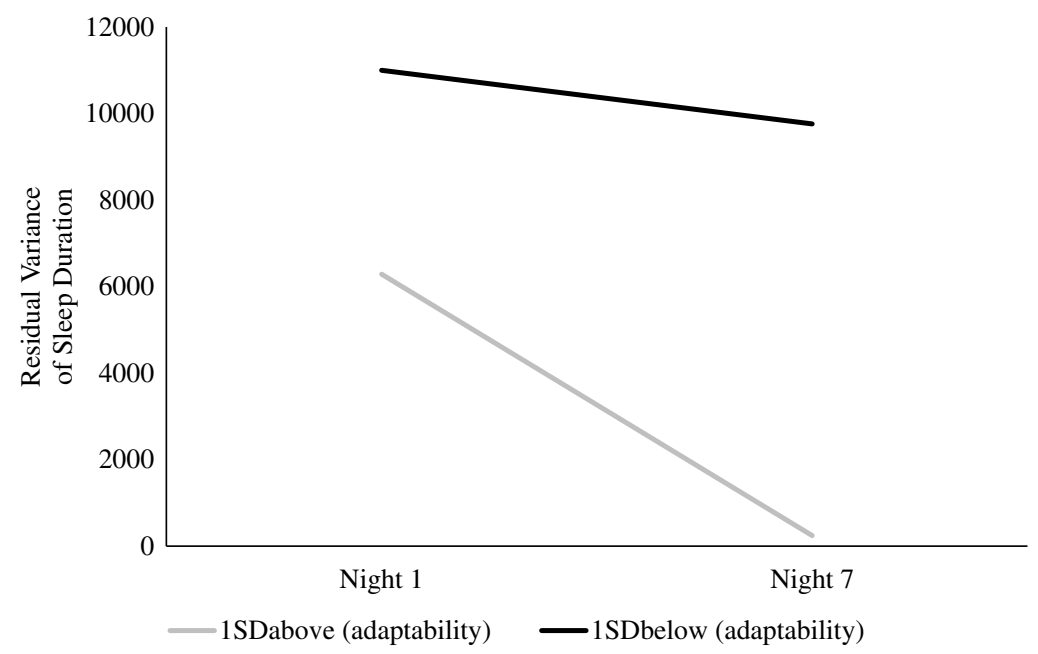

Note. Time $\times$ Predictor formula for graphing interaction terms: (a) $1 S D$ above at start of study $=\sigma^{2} \exp \left(2 \times \delta_{1} \times 0+2 \times \delta_{2} \times 1+2 \times \delta_{3} \times 0 \times 1\right)$. (b) $1 S D$ above at end of 7 days $=\sigma^{2} \exp \left(2 \times \delta_{1} \times 6+2 \times \delta_{2} \times 1+2 \times \delta_{3} \times 6 \times 1\right)$. (c) $1 S D$ below at start of study $=\sigma^{2} \exp \left(2 \times \delta_{1} \times 0+2 \times \delta_{2} \times-1+2 \times \delta_{3} \times 0 \times-1\right)$. (d) $1 S D$ below at end of 7 days $=\sigma^{2} \exp \left(2 \times \delta_{1} \times 6+2 \times \delta_{2} \times-1+2 \times \delta_{3} \times 6 \times-1\right)$.

evidenced substantial nightly fluctuations around this line of best fit. For these reasons, modeling temporal means and within-person variability permits inferences of emergent resilience along a continuum that differs in degree and kind (e.g., stable mean trend, high variability) rather than an arbitrary dichotomy of resilient or not.

Time is an essential consideration for advancing knowledge of emergent resilience and identifying opportune points at which to intervene. By definition, inferences regarding emergent resilience can be made only within the context of one's trajectory of functioning over a temporal period during and/or following the experience of heightened risk or vulnerability. Scholars define time according to four key dimensions of a phenomenon, event, or process, namely the temporal length (duration), number of times (frequency), when something occurs (timing), and temporal ordering (sequence; Aguinis \& Bakker, 2021, p. 3). Which of these four key elements of time is most essential to emergent resilience depends on the nature of the triggering stressor or adversity experience and indicators of functioning considered salient for this context. We focused on immediate, short-term emergent resilience in response to a 3-week long stressor because of the practical need for participants to recover quickly after a major stressor in preparation for subsequent training demands. Thus, we explicitly incorporated elements of duration (21 days) for the triggering stressor; duration (sleep minutes per night), frequency (7 nights of sleep), and timing (sleep time window where participants experienced the longest inactivity block) for the indicator of functioning; and sequence (temporal ordering) for the interaction between the stressor and indicators of functioning. Conceptually, therefore, our study design permits insight into short-term recovery dynamics in response to an extended stressor experience that might differ from long-term trajectories that span days, months, or even years (e.g., major surgery, geographical relocation).

In the present study, we focused on the objective elements of time to characterize the stressor experience and indicator of functioning for emergent resilience. Nevertheless, it is important to acknowledge that people can differ with respect to their perceptions of time (Shipp et al., 2009). Time can be broadly distinguished as objective (i.e., passage of clock time in linear, homogenous, and absolute terms) or subjective (i.e., individualized experiences of the passage of 
time in dynamic, heterogeneous, and interpretive terms; e.g., time flies or time is of the essence) in nature (Ancona et al., 2001; Shipp \& Cole, 2015). Time pressure, for example, is one of the most studied individual temporal states in organizational research (Tang et al., 2020); perceiving one has insufficient time to complete a task (time pressure) is distinct from objective elements of time that are externally imposed (time constraint). The subjective view of time is largely absent from existing work on emergent resilience, despite the centrality of people's experiences and interpretations of time as causal factors in stress (Eldor et al., 2017). Temporal focus, which represents the degree to which people allocate attention to the past, present, or future and mentally navigate between these temporal periods (Shipp et al., 2009), is one important consideration for emergent resilience. Systematically reflecting on past stressor experiences to augment learning and development is one promising approach to optimizing emergent resilience (Crane, Boga, et al., 2019; Crane, Searle, et al., 2019). In contrast, it is well established that ruminating about the past with respect to regrets, errors, or deficiencies is maladaptive for human functioning (e.g., Clancy et al., 2020; Ottaviani et al., 2016; Szabo et al., 2017). Thus, explicitly integrating elements of objective and subjective time and their interaction in future work on emergent resilience represents an exciting opportunity for conceptual precision and optimized translation of empirical findings into practice.

The conceptualization of resilience as an emergent outcome is agnostic to the capacities of the individual that underpin withstand or bounce back trajectories or the mechanisms by which they unfold in relation to heightened risk or vulnerability. Broadly speaking, resilience factors are resources that moderate or mediate the effect of stressor or adversity experiences on contextually salient indicators of functioning (Fritz et al., 2018). In the present study, we examined hair cortisol concentration to provide an assessment of accumulated environmental stress (Stalder et al., 2017), and adaptability as a potential resource that maximizes an individual's potential or readiness to mobilize selfregulatory strategies in ways that are synchronous with dynamic contextual factors (Martin et al., 2012). Keeping in mind that these interaction tests were sufficiently powered to detect moderate-to-large effects only, our findings provide insights that may inform future work rather than empirical evidence regarding their salience as resilience factors. Of particular relevance here is the differential effects of these factors on key parameters of the models; for instance, biological stress primarily influenced the total sleep duration on the first night of the 7-day monitoring period, whereas adaptability largely affected temporal changes in the within-person residual variances. These general trends have intuitive appeal because hair cortisol concentration is robust to acute variations in contextual (e.g., events) and psychological factors (e.g., moods) that are demonstrated in salivary cortisol (Stalder et al., 2017), whereas adaptability is sensitive to such person-situation interaction dynamics (Zacher, 2015, 2016). Thus, disentangling mean level trends from changes in within-person variability over time offers a new perspective from which to identify salient risk or resilience factors and the processes by which they unfold in relation to heightened risk or vulnerability. An important consideration for future research is to examine time-variant and time-invariant resilience factors because the degree to which a capacity or process is protective or adaptive may change over time.

\section{Strengths and Limitations}

Key strengths of this study include a synergy between concept, operationalization, and method; a sample and design suitable to the examination of short-term temporal dynamics in response to a significant stressor; and an innovative statistical model that offers flexibility for disentangling temporal dynamics of mean levels and within-person variability of indicators of functioning for emergent resilience. Nevertheless, there are several key limitations to keep in mind when interpreting these data. First, although the sample size was adequately powered to examine temporal changes in within-person variability in sleep functioning, the design and test combination was insufficiently powered to detect small interaction effects that might reflect practically salient antecedents of these temporal dynamics. We provide $\mathrm{R}$ scripts on the OSF project page for readers interested in conducting their own power simulations to determine a suitable combination of people (Level 1) and assessment points (Level 2). Second, we focused on one indicator of emergent resilience to synergize pragmatics and concept, yet acknowledge that resilient 
trajectories in one domain (e.g., sleep functioning) can co-exist with deficit patterns in other areas (e.g., social disconnection; Infurna \& Luthar, 2018). Third, we examined linear changes in mean levels and intra-individual variability only because this model aligned most closely with our conceptualization of "bounce back" resilience. Nevertheless, we acknowledge that non-linear trajectories might also offer interesting perspectives on the operationalization of emergent resilience (e.g., variability reduces then subsequently increases, discontinuous). The analytical framework employed here is able to accommodate non-linear trajectories, yet their interpretation is challenging and their inclusion would increase the model complexity considerably. The statistical power for detecting such effects has not been systematically studied in field data so far (Lang et al., 2019). Finally, we examined only two time-invariant risk or resilience factors as predictors of key parameters in the model. Scholars have recently proposed a reconceptualization of resilience factors as dynamic networks characterized by multiple factors interconnected via causal associations with each other (Kalisch et al., 2019). Consider the example of curiosity, stressor reflections, and self-regulation; a strong disposition to seek out new information and experiences (curiosity; Kashdan et al., 2020) may encourage one to engage systematically in reflections on their experiences with stressors (Crane, Boga, et al., 2019), which in turn may enable them to identify self-regulatory strategies that they have available to them to deal with similar stressors in the future (e.g., social support) or which they may need to learn (e.g., emotional flexibility). When combined with a temporal perspective, the network approach can shed light on the associations among resilience factors throughout different phases after experiencing an adversity. For example, resilience factors may be weakly interconnected with indicators of functioning during the initial phase after stressor or adversity exposure, yet the degree of interconnectedness may become stronger as time progresses.

\section{Conclusion}

The concept of resilience evokes substantial appeal across the human sciences where optimal functioning in the face of heightened risk or vulnerability is the goal. We proposed a conceptualization of emergent resilience as one that reflects a system's trajectory of functioning following exposure to major stressors or adversities that can be operationalized via temporal changes in mean levels and within-person variability of indices of functioning. Using data collected with military personnel after a major stressor, we showcased the potential of this alternative conceptualization and operationalization for the study of emergent resilience and included analysis scripts for readers who may be interested in adapting this approach in their future work. The focus on sleep functioning offers important foundations for practical innovations for occupational health psychologists interested in minimizing the deleterious effects of sleep disturbances on employee health, safety, and performance. Maximizing synergies between concept, operationalization, and method is essential for the development of pragmatic and scalable interventions for optimizing resilience.

\section{References}

Aguinis, H., \& Bakker, R. M. (2021). Time is of the essence: Improving the conceptualization and measurement of time. Human Resource Management Review, 31, Article 100763. https://doi.org/10 .1016/j.hrmr.2020.100763

Ancona, D. G., Okhuysen, G. A., \& Perlow, L. A. (2001). Taking time to integrate temporal research. Academy of Management Review, 26(4), 512-529. https://doi.org/10.5465/amr.2001.5393887

Bei, B., Wiley, J. F., Trinder, J., \& Manber, R. (2016). Beyond the mean: A systematic review on the correlates of daily intraindividual variability of sleep/wake patterns. Sleep Medicine Reviews, 28, 108-124. https://doi.org/10.1016/j.smrv.2015.06.003

Bonanno, G. A. (2004). Loss, trauma, and human resilience: Have we underestimated the human capacity to thrive after extremely aversive events? American Psychologist, 59(1), 20-28. https:// doi.org/10.1037/0003-066X.59.1.20

Bonanno, G. A., \& Diminich, E. D. (2013). Annual research review: Positive adjustment to adversitytrajectories of minimal-impact resilience and emergent resilience. Journal of Child Psychology and Psychiatry, and Allied Disciplines, 54(4), 378-401. https://doi.org/10.1111/jcpp.12021

Bonanno, G. A., \& Mancini, A. D. (2012). Beyond resilience and PTSD: Mapping the heterogeneity of responses to potential trauma. Psychological Trauma: Theory, Research, Practice, and Policy, 4(1), 74-83. https://doi.org/10 .1037/a0017829 
Bonanno, G. A., Romero, S. A., \& Klein, S. I. (2015). The temporal elements of psychological resilience: An integrative framework for the study of individuals, families, and communities. Psychological Inquiry, 26(2), 139-169. https://doi.org/10.1080/ 1047840X.2015.992677

Bonde, J. P. E. (2008). Psychosocial factors at work and risk of depression: A systematic review of the epidemiological evidence. Occupational and Environmental Medicine, 65(7), 438-445. https:// doi.org/10.1136/oem.2007.038430

Vidal Bustamante, C. M., Rodman, A. M., Dennison, M. J., Flournoy, J. C., Mair, P., \& McLaughlin, K. A. (2020). Within-person fluctuations in stressful life events, sleep, and anxiety and depression symptoms during adolescence: A multiwave prospective study. Journal of Child Psychology and Psychiatry, and Allied Disciplines, 61, 1116-1125. https:// doi.org/10.1111/jcpp.13234

Clancy, F., Prestwich, A., Caperon, L., Tsipa, A., \& O'Connor, D. B. (2020). The association between worry and rumination with sleep in non-clinical populations: A systematic review and metaanalysis. Health Psychology Review, 14(4), 427-448. https://doi.org/10.1080/17437199.2019 .1700819

Cohen, S., Murphy, M. L. M., \& Prather, A. A. (2019). Ten surprising facts about stressful life events and disease risk. Annual Review of Psychology, 70(1), 577-597. https://doi.org/10.1146/annurev-psych010418-102857

Cooper, C. L., Dewe, P. J., \& O'Driscoll, M. P. (2001). Organizational stress: A review and critique of theory, research, and applications. Sage Publications.

Cooper, G. A. A., Kronstrand, R., \& Kintz, P., \& the Society of Hair Testing. (2012). Society of Hair Testing guidelines for drug testing in hair. Forensic Science International, 218(1-3), 20-24. https:// doi.org/10.1016/j.forsciint.2011.10.024

Couch, D. (2008). Chosen soldier: The making of a special forces warrior. Three Rivers Press.

Crane, M. F., Boga, D., Karin, E., Gucciardi, D. F., Rapport, F., Callen, J., \& Sinclair, L. (2019). Strengthening resilience in military officer cadets: A group-randomized controlled trial of coping and emotion regulatory self-reflection training. Journal of Consulting and Clinical Psychology, 87(2), 125-140. https://doi.org/10.1037/ccp0000356

Crane, M. F., Searle, B. J., Kangas, M., \& Nwiran, Y. (2019). How resilience is strengthened by exposure to stressors: The systematic self-reflection model of resilience strengthening. Anxiety, Stress, and Coping, 32(1), 1-17. https://doi.org/10.1080/1061 5806.2018.1506640

Eddy, P., Wertheim, E. H., Kingsley, M., \& Wright, B. J. (2017). Associations between the effort-reward imbalance model of workplace stress and indices of cardiovascular health: A systematic review and meta-analysis. Neuroscience and Biobehavioral Reviews, 83, 252-266. https://doi.org/10.1016/j.ne ubiorev.2017.10.025

Eldor, L., Fried, Y., Westman, M., Levi, A. S., Shipp, A. J., \& Slowik, L. H. (2017). The experience of work stress and the context of time: Analyzing the role of subjective time. Organizational Psychology Review, 7(3), 227-249. https://doi.org/10.1177/ 2041386617697506

Firth, J., Solmi, M., Wootton, R. E., Vancampfort, D., Schuch, F. B., Hoare, E., Gilbody, S., Torous, J., Teasdale, S. B., Jackson, S. E., Smith, L., Eaton, M., Jacka, F. N., Veronese, N., Marx, W., AshdownFranks, G., Siskind, D., Sarris, J., Rosenbaum, S., ... Stubbs, B. (2020). A meta-review of "lifestyle psychiatry": The role of exercise, smoking, diet and sleep in the prevention and treatment of mental disorders. World Psychiatry, 19(3), 360-380. https://doi.org/10.1002/wps.20773

Fortier-Brochu, E., Beaulieu-Bonneau, S., Ivers, H., \& Morin, C. M. (2012). Insomnia and daytime cognitive performance: A meta-analysis. Sleep Medicine Reviews, 16(1), 83-94. https://doi.org/10.1016/j .smrv.2011.03.008

Fritz, J., de Graaff, A. M., Caisley, H., van Harmelen, A.-L., \& Wilkinson, P. O. (2018). A systematic review of amenable resilience factors that moderate and/or mediate the relationship between childhood adversity and mental health in young people. Frontiers in Psychiatry, 9, Article 230. https://doi.org/10 $.3389 /$ fpsyt.2018.00230

Galatzer-Levy, I. R., Huang, S. H., \& Bonanno, G. A. (2018). Trajectories of resilience and dysfunction following potential trauma: A review and statistical evaluation. Clinical Psychology Review, 63, 41-55. https:// doi.org/10.1016/j.cpr.2018.05.008

Ganster, D. C., \& Rosen, C. C. (2013). Work stress and employee health: A multidisciplinary review. Journal of Management, 39(5), 1085-1122. https:// doi.org/10.1177/0149206313475815

Germain, A., \& Dretsch, M. (2016). Sleep and resilience-A call for prevention and intervention. Sleep (Basel), 39(5), 963-965. https://doi.org/10.5665/ sleep.5732

Grimm, K. J., \& Ram, N. (2018). Latent growth and dynamic structural equation models. Annual Review of Clinical Psychology, 14(1), 55-89. https:// doi.org/10.1146/annurev-clinpsy-050817-084840

Gucciardi, D. F., Crane, M., Ntoumanis, N., Parker, S. K., Thøgersen-Ntoumani, C., Ducker, K. J., Peeling, P., Chapman, M. T., Quested, E., \& Temby, P. (2018). The emergence of team resilience: A multilevel conceptual model of facilitating factors. Journal of Occupational and Organizational Psychology, 91(4), 729-768. https://doi.org/10.1111/joop.12237

Gucciardi, D. F., Lines, R. L. J., Ducker, K. J., Peeling, P., Chapman, M. T., \& Temby, P. (2021). Mental 
toughness as a psychological determinant of behavioral perseverance in special forces selection. Sport, Exercise, and Performance Psychology, 10(1), 164-175. https://doi.org/10.1037/spy0000208

Hassard, J., Teoh, K. R. H., Visockaite, G., Dewe, P., \& Cox, T. (2018). The cost of work-related stress to society: A systematic review. Journal of Occupational Health Psychology, 23(1), 1-17. https:// doi.org/10.1037/ocp0000069

Hayes, A. F., \& Coutts, J. J. (2020). Use Omega rather than Cronbach's $\alpha$ for estimating reliability. But ... .. Communication Methods and Measures, 14(1), 1-24. https://doi.org/10.1080/19312458.2020. 1718629

Hirotsu, C., Tufik, S., \& Andersen, M. L. (2015). Interactions between sleep, stress, and metabolism: From physiological to pathological conditions. Sleep Science, 8(3), 143-152. https://doi.org/10 .1016/j.slsci.2015.09.002

Houben, M., Van Den Noortgate, W., \& Kuppens, P. (2015). The relation between short-term emotion dynamics and psychological well-being: A metaanalysis. Psychological Bulletin, 141(4), 901-930. https://doi.org/10.1037/a0038822

Infurna, F. J., \& Grimm, K. J. (2017). The use of growth mixture modeling for studying resilience to major life stressors in adulthood and old age: Lessons for class size and identification and model selection. The Journals of Gerontology: Series B, 73(1), 148-159. https://doi.org/10.1093/geronb/gbx019

Infurna, F. J., \& Luthar, S. S. (2018). Re-evaluating the notion that resilience is commonplace: A review and distillation of directions for future research, practice, and policy. Clinical Psychology Review, 65, 43-56. https://doi.org/10.1016/j.cpr.2018.07.003

Irwin, M. R. (2015). Why sleep is important for health: A psychoneuroimmunology perspective. Annual Review of Psychology, 66(1), 143-172. https:// doi.org/10.1146/annurev-psych-010213-115205

Kalisch, R., Baker, D. G., Basten, U., Boks, M. P., Bonanno, G. A., Brummelman, E., Chmitorz, A., Fernàndez, G., Fiebach, C. J., Galatzer-Levy, I., Geuze, E., Groppa, S., Helmreich, I., Hendler, T., Hermans, E. J., Jovanovic, T., Kubiak, T., Lieb, K., Lutz, B., ... Kleim, B. (2017). The resilience framework as a strategy to combat stress-related disorders. Nature Human Behaviour, 1(11), 784790. https://doi.org/10.1038/s41562-017-0200-8

Kalisch, R., Cramer, A. O. J., Binder, H., Fritz, J., Leertouwer, I., Lunansky, G., Meyer, B., Timmer, J., Veer, I. M., \& van Harmelen, A.-L. (2019). Deconstructing and reconstructing resilience: A dynamic network approach. Perspectives on Psychological Science, 14, 765-777. https://doi.org/10 $.1177 / 1745691619855637$

Kalisch, R., Müller, M. B., \& Tüscher, O. (2015). A conceptual framework for the neurobiological study of resilience. Behavioral and Brain Sciences,
38, Article e92. https://doi.org/10.1017/S0140 $525 \mathrm{X} 1400082 \mathrm{X}$

Kashdan, T. B., Goodman, F. R., Disabato, D. J., McKnight, P. E., Kelso, K., \& Naughton, C. (2020). Curiosity has comprehensive benefits in the workplace: Developing and validating a multidimensional workplace curiosity scale in United States and German employees. Personality and Individual Differences, 155, Article 109717. https://doi.org/10 .1016/j.paid.2019.109717

Kashdan, T. B., \& Rottenberg, J. (2010). Psychological flexibility as a fundamental aspect of health. Clinical Psychology Review, 30(7), 865-878. https://doi.org/ 10.1016/j.cpr.2010.03.001

Kim, E.-J., \& Dimsdale, J. E. (2007). The effect of psychosocial stress on sleep: A review of polysomnographic evidence. Behavioral Sleep Medicine, 5(4), 256-278. https://doi.org/10.1080/15402000 701557383

Kozlowski, S. W. J., Chao, G. T., Grand, J. A., Braun, M. T., \& Kuljanin, G. (2013). Advancing multilevel research design: Capturing the dynamics of emergence. Organizational Research Methods, 16(4), 581-615. https://doi.org/10.1177/1094428113493119

Kuppens, T., \& Yzerbyt, V. Y. (2014). Predicting variability: Using multilevel modelling to assess differences in variance. European Journal of Social Psychology, 44(7), 691-700. https://doi.org/10 .1002/ejsp. 2028

Lang, J. W. B., Bliese, P. D., \& Runge, J. M. (2019). Detecting consensus emergence in organizational multilevel data: Power simulations. Organizational Research Methods. Advance online publication. https://doi.org/10.1177/1094428119873950

Lang, J. W. B., Bliese, P. D., \& de Voogt, A. (2018). Modeling consensus emergence in groups using longitudinal multilevel methods. Personnel Psychology, 71(2), 255-281. https://doi.org/10 $.1111 /$ peps. 12260

Lazarus, R. S., \& Folkman, S. (1984). Stress, appraisal, and coping. Springer.

Lester, H. F., Cullen-Lester, K. L., \& Walters, R. W. (2019). From Nuisance to novel research questions: Using multilevel models to predict heterogeneous variances. Organizational Research Methods. Advance online publication. https://doi.org/10 $.1177 / 1094428119887434$

Lim, J., \& Dinges, D. F. (2010). A meta-analysis of the impact of short-term sleep deprivation on cognitive variables. Psychological Bulletin, 136(3), 375-389. https://doi.org/10.1037/a0018883

Litwiller, B., Snyder, L. A., Taylor, W. D., \& Steele, L. M. (2017). The relationship between sleep and work: A meta-analysis. Journal of Applied Psychology, 102(4), 682-699. https://doi.org/10.1037/ ap10000169

Liu, J. J. W., Reed, M., \& Girard, T. A. (2017). Advancing resilience: An integrative, multi-system 
model of resilience. Personality and Individual Differences, 111, 111-118. https://doi.org/10.1016/ j.paid.2017.02.007

Magee, L. (1990). R2 measures based on Wald and likelihood ratio joint significance tests. The American Statistician, 44(3), 250-253. https:// doi.org/10.1080/00031305.1990.10475731

Martin, A. J., Nejad, H., Colmar, S., \& Liem, G. A. D. (2012). Adaptability: Conceptual and empirical perspectives on responses to change, novelty and uncertainty. Journal of Psychologists and Counsellors in Schools, 22(1), 58-81. https://doi.org/10 .1017/jgc.2012.8

Maynard, M. T., Kennedy, D. M., \& Sommer, S. A. (2015). Team adaptation: A fifteen-year synthesis (1998-2013) and framework for how this literature needs to "adapt" going forward. European Journal of Work and Organizational Psychology, 24(5), 652-677. https://doi.org/10.1080/1359432X.2014 .1001376

McNeish, D. (2020). Specifying location-scale models for heterogeneous variances as multilevel SEMs. Organizational Research Methods. Advance online publication. https://doi.org/10.1177/1094428120913083

Nindl, B. C., Billing, D. C., Drain, J. R., Beckner, M. E., Greeves, J., Groeller, H., Teien, H. K., Marcora, S., Moffitt, A., Reilly, T., Taylro, N. A. S., Young, A. J., \& Friedl, K. E. (2018). Perspectives on resilience for military readiness and preparedness: Report of an international military physiology roundtable. Journal of Science and Medicine in Sport, 21(11), 1116-1124. https://doi.org/10 $.1016 /$ j.jsams.2018.05.005

Ottaviani, C., Thayer, J. F., Verkuil, B., Lonigro, A., Medea, B., Couyoumdjian, A., \& Brosschot, J. F. (2016). Physiological concomitants of perseverative cognition: A systematic review and metaanalysis. Psychological Bulletin, 142(3), 231-259. https://doi.org/10.1037/bul0000036

Parrino, L., \& Vaudano, A. E. (2018). The resilient brain and the guardians of sleep: New perspectives on old assumptions. Sleep Medicine Reviews, 39, 98-107. https://doi.org/10.1016/j.smrv.2017.08.003

Pinheiro, J., \& Bates, D. (2006). Mixed-effects models in $S$ and S-PLUS. Springer Science \& Business Media.

R Development Core Team. (2018). R: A language and environment for statistical computing. $\mathrm{R}$ foundation for statistical computing.

Razinskas, S., \& Hoegl, M. (2020). A multilevel review of stressor research in teams. Journal of Organizational Behavior, 41(2), 185-209. https:// doi.org/10.1002/job.2420

Rowe, M., McCrae, C., Campbell, J., Horne, C., Tiegs, T., Lehman, B., \& Cheng, J. (2008). Actigraphy in older adults: Comparison of means and variability of three different aggregates of measurement. Behavioral Sleep Medicine, 6(2), 127-145. https://doi.org/10.1080/1540200080195 2872

Sadeh, A., \& Gruber, R. (2002). Stress and sleep in adolescence: A clinical-developmental perspective. In Adolescent sleep patterns: Biological, social, and psychological influences (pp. 236-253). Cambridge University Press. https://doi.org/10 $.1017 /$ CBO9780511499999.017

Seelig, A. D., Jacobson, I. G., Donoho, C. J., Trone, D. W., Crum-Cianflone, N. F., \& Balkin, T. J. (2016). Sleep and health resilience metrics in a large military cohort. Sleep (Basel), 39(5), 1111-1120. https://doi.org/10.5665/sleep.5766

Segerstrom, S. C., Sephton, S. E., \& Westgate, P. M. (2017). Intraindividual variability in cortisol: Approaches, illustrations, and recommendations. Psychoneuroendocrinology, 78, 114-124. https:// doi.org/10.1016/j.psyneuen.2017.01.026

Shipp, A. J., \& Cole, M. S. (2015). Time in individuallevel organizational studies: What is it, how is it used, and why isn't it exploited more often? Annual Review of Organizational Psychology and Organizational Behavior, 2(1), 237-260. https://doi.org/10 .1146/annurev-orgpsych-032414-111245

Shipp, A. J., Edwards, J. R., \& Lambert, L. S. (2009). Conceptualization and measurement of temporal focus: The subjective experience of the past, present, and future. Organizational Behavior and Human Decision Processes, 110(1), 1-22. https:// doi.org/10.1016/j.obhdp.2009.05.001

Skoluda, N., Dettenborn, L., Stalder, T., \& Kirschbaum, C. (2012). Elevated hair cortisol concentrations in endurance athletes. Psychoneuroendocrinology, 37(5), 611-617. https://doi.org/10 .1016/j.psyneuen.2011.09.001

Stalder, T., Steudte-Schmiedgen, S., Alexander, N., Klucken, T., Vater, A., Wichmann, S., Kirschbaum, C., \& Miller, R. (2017). Stress-related and basic determinants of hair cortisol in humans: A metaanalysis. Psychoneuroendocrinology, 77, 261-274. https://doi.org/10.1016/j.psyneuen.2016.12.017

Starcke, K., \& Brand, M. (2016). Effects of stress on decisions under uncertainty: A meta-analysis. Psychological Bulletin, 142(9), 909-933. https:// doi.org/10.1037/bul0000060

Szabo, Y. Z., Warnecke, A. J., Newton, T. L., \& Valentine, J. C. (2017). Rumination and posttraumatic stress symptoms in trauma-exposed adults: A systematic review and meta-analysis. Anxiety, Stress, and Coping, 30(4), 396-414. https:// doi.org/10.1080/10615806.2017.1313835

Tang, S., Richter, A. W., \& Nadkarni, S. (2020). Subjective time in organizations: Conceptual clarification, integration, and implications for future research. Journal of Organizational Behavior, 4l(2), 210-234. https://doi.org/10.1002/job.2421 
Uehli, K., Mehta, A. J., Miedinger, D., Hug, K., Schindler, C., Holsboer-Trachsler, E., Leuppi, J. D., \& Künzli, N. (2014). Sleep problems and work injuries: A systematic review and meta-analysis. Sleep Medicine Reviews, 18(1), 61-73. https:// doi.org/10.1016/j.smrv.2013.01.004

van Hees, V. T., Sabia, S., Anderson, K. N., Denton, S. J., Oliver, J., Catt, M., Abell, J. G., Kivimäki, M., Trenell, M. I., \& Singh-Manoux, A. (2015). A novel, open access method to assess sleep duration using a wrist-worn accelerometer. PLOS ONE, 10(11), Article e0142533. https://doi.org/10.1371/ journal.pone.0142533

van Hees, V. T., Sabia, S., Jones, S. E., Wood, A. R., Anderson, K. N., Kivimäki, M., Frayling, T. M., Pack, A. I., Bucan, M., Trenell, M. I., Mazzotti, D. R., Gehrman, P. R., Singh-Manoux, B. A., \& Weedon, M. N. (2018). Estimating sleep parameters using an accelerometer without sleep diary. Scientific Reports, 8(1), Article 12975. https://doi.org/10 .1038/s41598-018-31266-z

Veeramachaneni, K., Slavish, D. C., Dietch, J. R., Kelly, K., \& Taylor, D. J. (2019). Intraindividual variability in sleep and perceived stress in young adults. Sleep Health, 5(6), 572-579. https://doi.org/ 10.1016/j.sleh.2019.07.009
Wickens, C. D., Hutchins, S. D., Laux, L., \& Sebok, A. (2015). The impact of sleep disruption on complex cognitive tasks: A meta-analysis. Human Factors, 57(6), 930-946. https://doi.org/ 10.1177/0018720815571935

Yin, J., Jin, X., Shan, Z., Li, S., Huang, H., Li, P., Peng, X., Peng, Z., Yu, K., Bao, W., Chen, X., \& Liu, L. (2017). Relationship of sleep duration with all-cause mortality and cardiovascular events: A systematic review and dose-response meta-analysis of prospective cohort studies. Journal of the American Heart Association, 6(9), Article e005947. https://doi.org/10.1161/JAHA.117.005947

Zacher, H. (2015). Daily manifestations of career adaptability: Relationships with job and career outcomes. Journal of Vocational Behavior, 91, 76-86. https://doi.org/10.1016/j.jvb.2015.09.003

Zacher, H. (2016). Within-person relationships between daily individual and job characteristics and daily manifestations of career adaptability. Journal of Vocational Behavior, 92, 105-115. https://doi.org/10.1016/j.jvb.2015.11.013

Received September 1, 2020 Revision received March 30, 2021 Accepted April 1, 2021 